\title{
Evaluation of Multidisciplinary Design Optimization Methods and Applying Single Level Frameworks in Unmanned Aerial Vehicle (UAV) Design
}

\author{
Majid Hosseini", Mehran Nosratollahi and Hossein Sadati \\ Aerospace Engineering, Aerospace Faculty, Malek Ashtar University of Technology, Tehran, Iran; \\ Mjdhosseini@mut.ac.ir, Nosratollahi@mut.ac.ir, hsadati@aut.ac.ir
}

\begin{abstract}
Objectives: Evaluation of Multidisciplinary Design Optimization (MDO) methods, comparison of advantages and disadvantages of them by applying single level frameworks in design of UAVs using genetic algorithm optimization and Sequential Quadratic Programming (SQP). Methods/Statistical Analysis: Multidisciplinary design optimization methods are divided into 2 overall single level and multilevel frameworks, mathematically. Frameworks under investigation here are: Multi Disciplinary Feasibility (MDF), All At Once (AAO) as single level frameworks and Collaborative Optimization (CO) in addition to Bi-Level Integrated System Synthesis (BLISS) as bi-level frameworks. Selection criteria of appropriate design framework include simplicity of algorithm, quick response as well as degree of convergence in finding optimal answers. Findings: in accordance with the aforementioned criteria, single level methods are superior to multilevel ones. Anyway, no method or framework could be considered as superior; instead, appropriate design framework according to each application should be selected. Finally, single level methods have been used in UAVs design according to which, MDF framework holds higher convergence capability than AAO, though with higher run time in comparison to AAO. Applications /Improvements: single level methods have been used in UAVs design and Global Hawk (RQ-4B) is redesigned for implementation and comparison.
\end{abstract}

Keywords: MDO, Multidisciplinary Design Optimization Frameworks, Systemic Design, Unmanned Aerial Vehicles Design

\section{Introduction}

Multidisciplinary design optimization has been applied in various engineering fields such as steel and concrete systems' design in civil engineering and or designing mechanisms, heating systems, etc. in mechanical engineering. But, one of the main contexts applying MDO is current designs in aerospace field. Method of designing airplanes was changed due to two main developments in aviation industry during 1970-1990. First, there was computer aided design, allowing quick change and analysis in design. Second, there was transformation of functional-based purchase policy of most airlines and military organizations, especially USA army to a method emphasizing life span and costs. The same caused arising of multidisciplinary design optimization methods].
Designing complicated and large systems such as aerospace vehicles requires appropriate compromise for gaining balance between multiple coupled targets. The targets include high performance and low costs. The sooner these compromises are understood in design process, the more technology, programming and cost related risks could be minimized. Conceptual design aims at specifying changing procedure and scope of compromise between answers in preliminary stages of design, while flexibility in design still exists and significant percentage of life cost still untouched. An aerial vehicle conceptual design procedure determines configuration of an assignment's requirement. This configuration is characterized by high performance (usually interpreted as low weight). In order to optimize the results in conceptual design phase, at least we have to consider the following points: 
1. Development of conceptual analysis, modeling and those instruments providing principle relationships between design variables and system targets with sufficient degree of assurance.

2. Development of some methods for coordinating engineering analyses and optimization of the system as a whole.

The second target mentioned above is accessible via multidisciplinary design optimization at conceptual level of design. There are complicated relationships existing between assignment requirements, constraints, design sub-systems and contradicted targets which could be coordinated using a suitable strategy of optimization. Multidisciplinary design optimization or coordinating between multidisciplinary analyses makes understandable more effective solutions during design and optimization of complicated systems. This allows system engineers to look for vast scope of compromise in a systematic and thoughtful way and consider more structures in conceptual design phase and before concentrating on final design. Preliminary application of optimization in aerospace industries is accompanied by optimization of sub-systems or components such as aerodynamic shape, orbital path, as well as optimization of sub-systems altogether. Anyway, an optimized systemic compound always will not be created through optimization of subsystems. In aerospace engineering, MDO was first applied in design of airplane and to date the method has been used in academic works and manufactured airplanes? In have used three different methods for optimization of reusable satellite carriers which are: synthetic as well as modified synthetic optimization and incorporation of bilevel integrated systems. Conceptual designing of launch vehicles has been done through applying multidisciplinary design optimization ${ }^{\beta-9}$. Conceptual designing of satellites as well as aerospace transportation systems has been performed, applying multidisciplinary design optimization ${ }^{10-13}$ and Conceptual designing of airplane is done taking advantage of multidisciplinary design

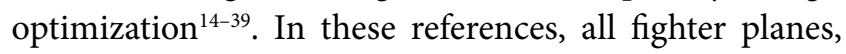
passenger planes, conventional planes and unmanned aerial vehicles (blended wing body and conventional) are considered. In a systemic attitude towards previous studies, applied design algorithms are: MDOs methods, in different frameworks such as $\mathrm{AAO}, \mathrm{MDF}, \mathrm{CO}$, and BLISS which are made compatible to different optimization methods like evolutionary algorithms and Steepest Descent. Mostly, design criteria are minimum cost, minimum weight and minimum drag under constraints of scenario performance and functional capability. New studies have paid attention to study and development of novel design methods and applying optimized and efficient frameworks in various fields including aerospace science in a way that application of MDO methods with various single level or multilevel frameworks in aerospace vehicles such as airplane, launch vehicles and satellite are seen referring to reliable papers and theses and are considered as a current theme up to date.

The paper is aiming at evaluation of multidisciplinary design optimization algorithms, implementation of single level frameworks in UAVs design as a case study and their comparison. Section 2, develops sub-systems and subjects involved in modeling design, as well as proposed algorithm for conceptual design of UAV based on multidisciplinary design optimization method in single level frameworks, using genetic algorithm optimization and SQP, which is considered as a new work in terms of optimization method. In section 4, redesign of Global Hawk UAV will be made, using prepared algorithm and comparison will be made between single level structures while validating multidisciplinary design optimization algorithm.

\section{Multidisciplinary Design Optimization Methods}

$\mathrm{MDO}$ is a branch of engineering science, applying optimization methods for resolving design problems with multiple contexts and themes having coupled parameters. The method is called multidisciplinary optimization or Multidisciplinary System Design Optimization (MSDO). The method allows designers to consider related themes simultaneously. Today's advanced aerospace vehicles have been transformed to most complex systems full of scientific branches with mutual effects, whereas, their final performance is associated with thousands of involved equations. Some of these equations are of high scrutiny and some beyond basic power of selection and judgment for the purpose of detailed assessment. This constant obsession could be expressed as: "how to decide to change what and to what extent? While each component influencing other components!" The answer could be looked for in MDO method. Integrated design procedure in reality wants to find a resolution for the same concern. Information resulted from analyses made in 
design process should be provided in easily interpretable formats. Multidisciplinary Optimization could be used as a quicker and accurate method for designing complicated systems.

\subsection{Evaluation of Multidisciplinary Design Optimization Methods}

By nature, MDO method has more benefits than traditional sequential design, including higher speed, more effective optimization, removing association and coupling between special work groups and high flexibility against changes in design in each sub-system. In addition to the above, the method with available multiple design algorithms and templates provides the designer with various choices of selection. Each of prepared algorithms of MDO has advantages in comparison to other algorithms, of course with some weak points as a consequence. This is why, in conceptual design phase, in addition to good knowledge and perspective necessity with regard to type of problem, degree of coupling between sub-systems, mode and design number of variables, etc., being familiar to function and implementation of MDO algorithms is also a must in order for selecting best algorithm to achieve design goal through minimum time and cost. The paper, tries at least to guide and be helpful to systemic designers to become familiar with the concept of MDO and select an appropriate design algorithm. Table 1 and Table 2, provide some comparison criteria between introduced algorithms, extracted upon authors' experiments regarding implementation of these algorithms, as well as results presented in reliable references. Scores in Table 2 are between 1 and 3 , respectively meaning weak, average and good. According to these tables, MDF and AAO methods are superior to others, but one should note that generally superiority of one framework or method to other is not feasible. Instead, an appropriate structure of design should be selected according to each problem and function.

Table 1. Grading the MDO methods

\begin{tabular}{lcccc}
\hline Criteria & MDF & AAO & CO & BLISS \\
\hline Implementation difficulty & 3 & 3 & 2 & 1 \\
Time & 2 & 3 & 1 & 1 \\
Optimization \& Convergence & 3 & 1 & 2 & 3 \\
Sum of results & 8 & 7 & 5 & 5 \\
\hline
\end{tabular}

Table 2. Comparison of advantages and disadvantages of MDO methods

\begin{tabular}{lll}
\hline Method & Advantages & Disadvantages \\
\hline MDF & $\begin{array}{l}\text { Easy Implementation Maintain feasibility } \\
\text { during the design process }\end{array}$ & Increasing design time due to internal cycles \\
AAO & $\begin{array}{l}\text { Do not have internal cycles } \\
\text { CO }\end{array}$ & $\begin{array}{l}\text { Increasing performance by increasing coupling } \\
\text { feasibility during the design process }\end{array}$ \\
& $\begin{array}{l}\text { Independent optimization of subsystems or } \\
\text { disciplines }\end{array}$ & $\begin{array}{l}\text { Poor convergence for high coupling problems } \\
\text { A lot of nonlinear constraint }\end{array}$ \\
\multirow{2}{*}{ BLISS } & $\begin{array}{l}\text { Independent optimization of subsystems } \\
\text { Have a better performance in bi-level methods }\end{array}$ & $\begin{array}{l}\text { Complex formulations } \\
\text { A lot of nonlinear constraint }\end{array}$ \\
\hline
\end{tabular}

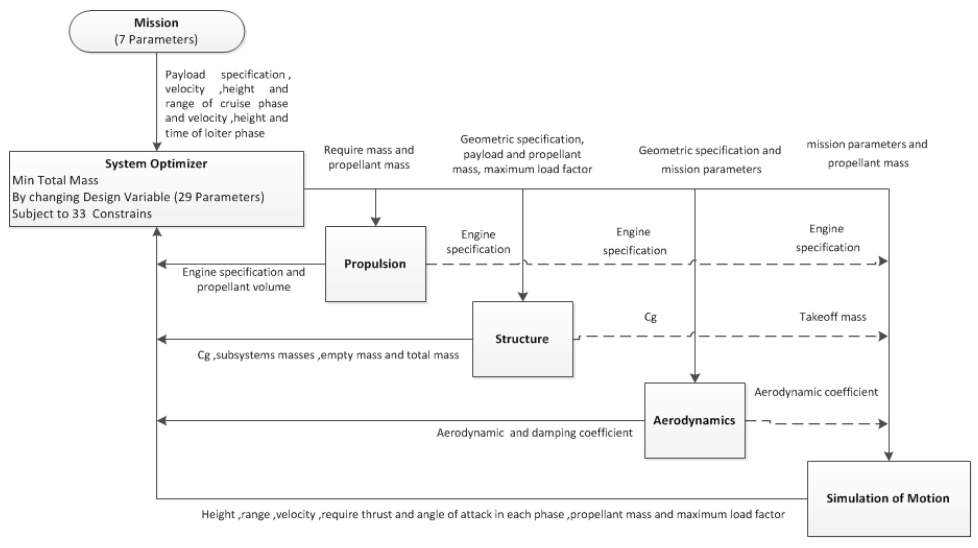

Figure 1. Multidisciplinary design optimization of UAV. 
Table 3. Outputs of design code for global hawk redesign

\begin{tabular}{lccccc}
\hline Section & \multicolumn{5}{c}{ Value } \\
\cline { 2 - 6 } & $\begin{array}{c}\text { Real } \\
\text { value }\end{array}$ & AAO & MDF & $\begin{array}{c}\text { AAO (difference } \\
\text { percent) }\end{array}$ & $\begin{array}{c}\text { MDF (difference } \\
\text { percent) }\end{array}$ \\
\hline Wing span (m) & 39.9 & 37 & 38.1 & 7.3 & 4.5 \\
Wing area (m $\left.{ }^{2}\right)$ & 63.02 & 55.1 & 57.4 & 12.6 & 8.9 \\
Body diameter (m) & 1.42 & 1.4 & 1.4 & 1.4 & 1.4 \\
Body length (m) & 14.5 & 13.9 & 14 & 4.1 & 3.4 \\
Empty mass (kg) & 5868 & 5222 & 5063 & 11.0 & 13.7 \\
Takeoff mass (Kg) & 14628 & 14083 & 12108 & 3.7 & 17.2 \\
Propellant mass (kg) & 7400 & 7500 & 5684 & 1.4 & 23.2 \\
Require Propellant mass (kg) & - & 6565 & 5655 & - & - \\
Number of optimization evaluation & - & 2696 & 1909 & - & - \\
Time of optimization & - & 13833 & 39947 & - & - \\
GA generation & - & 49 & 34 & - & - \\
\hline
\end{tabular}

\section{UAV Multidisciplinary Design Optimization Algorithm}

Following evaluation of multidisciplinary design optimization algorithms, here we provide appropriate algorithm for conceptual design of UAV. This algorithm is based on single level multidisciplinary design optimization methods in MDF and AAO framework, using combination of genetic algorithm optimization methods and SQP. Before presentation of design algorithm, it is necessary for various parts of UAV design to be identified, modeled and transformed to a software code. Another subjects involved in design are: aerodynamic, structure, propulsion and path simulation.

\section{Implementation of Multidisciplinary Optimization Design Single Level Structures and their Comparison}

Global Hawk (RQ-4B) as show in Figure 2 is redesigned for implementation and comparison of single level frameworks as well as validation of design code and the results have been analyzed.

To do so, mission information of this UAV were considered as design code input and the output extracted. Then, outputs were compared to real UAV information and design code percentage of error presented. Code inputs for Global Hawk redesign are: $575 \mathrm{~km} / \mathrm{h}$ of velocity cruise, 28 hours of flight endurance, maximum altitude of 18 kilometers and payload mass of $1360 \mathrm{~kg}$. Code output for Global Hawk redesign in two AAO and MDF frameworks are presented in following Table 3 . As seen in the table, result differences in AAO method with existing information regarding Global Hawk of some items such as overall mass, fuel mass, fuselage length and diameter is less than $5 \%$, in wingspan is $7.3 \%$ and in wing area and empty mass is about $12 \%$. Likewise, result differences in MDF method with existing information from Global Hawk is between 13\%-23\% in masses and less than 9\% in geometrical specifications. Following points could be referred to as the reasons for these differences:

- Lack of sufficient information about Global Hawk flight scenario;

- Lack of information about airfoil and lifting instruments at the time of takeoff and landing;

- Lack of information about accurate stall speed and some of functional parameters;

- Lack of information about payload geometric specifications, sub-systems layout and fuel;

- Lack of consideration of uncertainties.

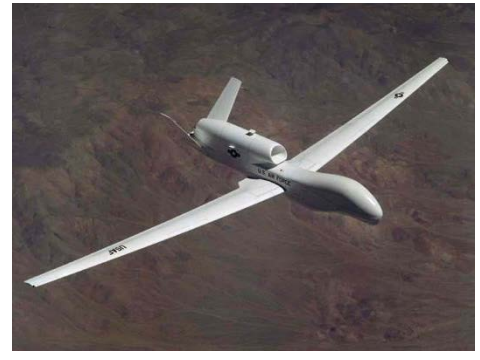

Figure 2. Global hawk UAV. 

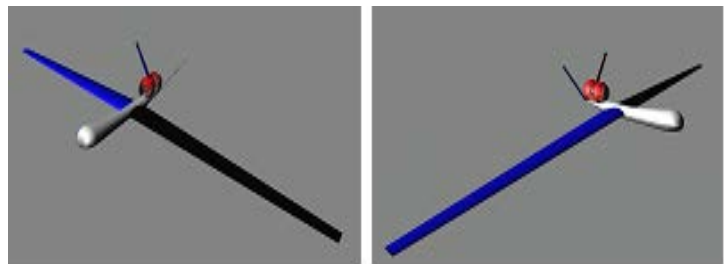

Figure 3. $3 \mathrm{D}$ view of redesigned UAV.

Looking at tables containing results, we may see that MDF framework has shown higher convergence capability in more time, in a way that overall mass resulted from MDF framework is about $2000 \mathrm{~kg}$ less than overall mass resulted from AAO framework and time span for MDF performance is about 26000 seconds more than time span for performance of AAO framework. Better convergence of MDF is due to the least difference attained between consumed and required fuel mass, however, in AAO framework, required fuel mass is about $950 \mathrm{~kg}$ less than UAV fuel. This means existence of capacity for decrease in fuel weight and in turn overall weight as a result, but no possibility for convergence of AAO. MDF is slower because of its internal cycles and although number of GA generations is less than AAO, calling for sub-systems in each evaluation of optimizer increases code performance time. It should be noted that optimization algorithm settings in both frameworks have been selected similarly for more accurate comparison. In Figure 3, 3D view and in figure 4 and figure 5 charts resulted from redesigned UAV simulation of motion, will be presented. As far as there is insignificant difference between software output results in both MDO frameworks, results from MDF framework have been presented.

\section{Conclusion}

Proposed multidisciplinary design optimization algorithm includes 11 common parameters, 15 uncommon parameters, 11 coupled parameters (total 37 design parameter) and 33 constraints. Through design of Global Hawk (operational UAV), intended code was implemented and validated and the two AAO and MDF

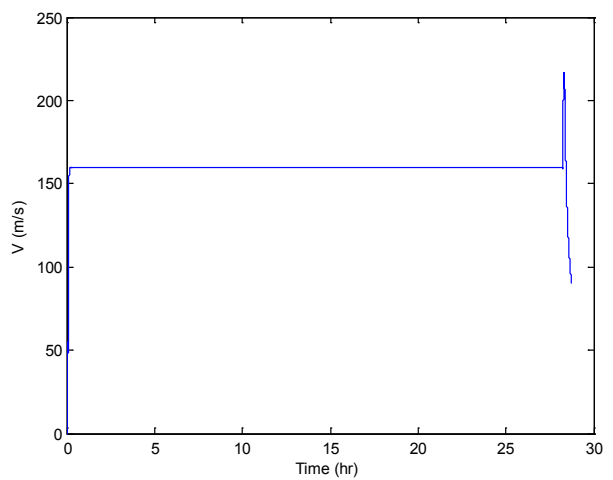

Figure 4. Height and velocity vs. time.
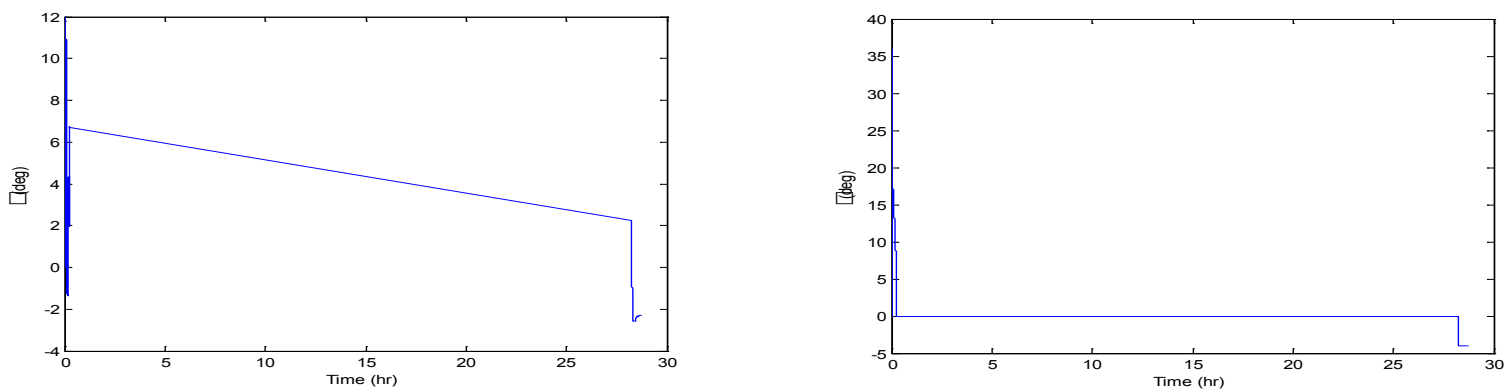

Figure 5. Angle of attack and path angle vs. time. 
frameworks were compared. According to the results, MDF shows higher convergence capability in more time span. Better convergence of MDF is due to the least difference attained between consumed fuel mass and required fuel mass, however, in AAO despite capacity for fuel weight (overall weight as a result) to be decreased, $\mathrm{AAO}$ is not capable of convergence. The reason for lower speed of MDF framework is its internal cycles. Although GA generations are less in numbers than AAO, calling for sub-systems in each evaluation of optimizer increases code performance time span.

\section{References}

1. Multidisciplinary Design Optimization strategy in MultiStage Launch Vehicle Conceptual Design [Internet]. [cited 2003 Aug]. Available from: http://www.casde.iitb.ac.in/ store/reports/phd/geethai-progsem-2003.pdf.

2. Nichols F, Brown B, John R. Evaluation of multidisciplinary optimization techniques applied to a reusable launch vehicle. Journal of Spacecraft and Rockets. 2006 Nov-Dec; 43(6):1289-300.

3. Stanley DO, Talay AT, Lepsch RA, Morris WD, Kathy EW. Conceptual design of a fully reusuable manned launch system. Journal of Spacecraft and Rockets. 1992 Jul-Aug; 29(4):529-37.

4. Braun RD, Powell RW, Lepsch RA. Stanley DO, Kroo IM. Comparison of two multidisciplinary optimization strategies for launch-vehicle design. Journal of Pacecraft and Rockets. 1995 May-Jun; 32(3):404-10.

5. Braun RD, Moore. Collaborative approach to launch vehicle design. Journal of Spacecraft and Rockets. 1997 JulAug; 34(4):478--6.

6. Tartabini PV, Wurster KE, Korte JJ, Lepsch RA. Multidisciplinary analysis of a lifting body launch vehicle. Journal of Spacecraft and Rockets. 2002 Sep-Oct; 39(5):788-95.

7. Schottle UM, Hilleshcimer M. Performance optimization of an airbreathing launch vehicle by a sequential trajectory optimization and vehicle design scheme. AIAA, Guidance, Navigation and Control Conference, New Orleans, LA; 1991 Aug.

8. Bayley DJ, Hartfield RJ, Burkhalter JE, Jenkins RM. Design optimization of a space launch vehicle using a genetic algorithm. Journal of Spacecraft and Rockets. 2008 Jul-Aug; 45(4):733-40.

9. Multidisciplinary cost and performance optimization of a two stage liquid propulsion based launch vehicle [Internet]. [cited 2008 apr 28]. Available from: http://arc.aiaa.org/doi/ abs/10.2514/6.2008-2642.

10. Advanced transport design using multidisciplinary design optimization [Internet]. [cited 1991 Sep 01]. Available from: http://ntrs.nasa.gov/search.jsp?R=19910069391.

11. A multi objective, multidisciplinary design optimiza- tion methodology for the conceptual design of distributed satellite system [Internet]. [cited 2002 May 01]. Available from: https://dspace.mit.edu/bitstream/handle/1721.1/16837/51283638-MIT.pdf?sequence $=2$.

12. Lawrence FR, Braun RD, Olds JR, Unal R. Multidisciplinary conceptual design optimization of space transportation systems. Journal of Aircraft. 1999 Jan-Feb; 36(1):218-26.

13. Tsuchiya, T, Mori. T. Multidisciplinary design optimization to future space transportation vehicle. AIAA paper 2002$5171 ; 2002$.

14. The suitability of selected multidisciplinary design and optimization techniques to conceptual aerospace vehicle design [Internet]. [cited 1992 Sep]. Available from: https:// smartech.gatech.edu/handle/1853/8443.

15. González LF, Srinivas K, Périaux J, Whitney EJ. Multidisciplinary design optimization of unmanned aerial vehicles (uav) using multi-criteria evolutionary algorithms. $6^{\text {th }}$ World Congresses of Structural and Multidisciplinary Optimization; 2005 May-Jun. p. 1-9.

16. Morris SJ, Kroo I. Aircraft design optimization with dynamic performance constraints. Journal of Aircraft. 1990 Dec; 27(12):1060-7.

17. Enhancing aircraft conceptual design using multidisciplinary optimization [Internet]. [cited 2002 May]. Available from: http://www.jdrr.yolasite.com/resources/Aeronautical_Engineering/BOOKS/AIRCRAFT\%20CONCEPTUAL\%20DESIGN\%20By\%20Daniel\%20P\%20Raymer.pdf.

18. Multidisciplinary and multiobjective design optimization of an unmanned combat aerial vehicle (ucav) [Internet]. [cited $2009 \mathrm{Feb}$ ]. Available from: http://citeseerx.ist.psu. edu/viewdoc/download?doi=10.1.1.633.1025\&rep=rep1\&type $=$ pdf.

19. Multidisciplinary aircraft conceptual design optimization considering fidelity uncertainties [Internet]. [cited 2010 Jan 01]. Available from: http://digital.library.ryerson.ca/islandora/object/RULA:1519.

20. Multidisciplinary design optimization in the conceptual design phase creating a conceptual design of the blended wing-body with the BLISS optimization strategy [Internet]. [cited 2011 Apr 20]. Available from: http://repository. tudelft.nl/islandora/object/uuid:d586ee6e-4815-4561-87d9 -6ae00bdb739e? collection=education

21. Aircraft multidisciplinary design optimization using design of experiments theory and response surface modeling methods [Internet]. [cited 1997 May]. Available from: https:// theses.lib.vt.edu/theses/public/etd-5742153049751491/etd. pdf.

22. A method for aircraft concept exploration using multicriteria interactive genetic algorithms [Internet]. [cited 2005 Nov 28]. Available from: https://smartech.gatech.edu/handle/1853/7571.

23. Multidisciplinary Design and Optimization (MDO) methodology for the aircraft conceptual design [Internet]. [cited 2009]. Available from: http://docs.lib.purdue.edu/dissertations/AAI3402368/.

24. Multidisciplinary Design Optimization of a strut-braced 
wing aircraft [Internet]. [cited 1998 Apr 13]. Available from: http://www.dept.aoe.vt.edu/ mason/Mason_f/GrasmeyerMS.pdf.

25. Multidisciplinary design techniques applied to conceptual aerospace vehicle design [Internet]. [cited 1993 Jan 01]. Available from: http://ntrs.nasa.gov/archive/nasa/casi.ntrs. nasa.gov/19940009145.pdf.

26. Safavi E, Munjulury RC, Ölvander J. Multidisciplinary optimization of aircraft vehicle system for conceptual analysis. Conference: 51st AIAA Aerospace Sciences Meeting including the New Horizons Forum and Aerospace Exposition; 2013 Jan. p. 1-9.

27. Rowell LF, Braun RD, Olds JR. Multidisciplinary conceptual design optimization of space transportation systems. Journal of Aircraft. 1999 Jan-Feb; 36(1):218-26.

28. Gora Z. Design challenges associated with development of a new generation UAV. Aircraft Engineering and Aerospace Technology. 2005 Oct; 77(5):361-8.

29. Lee DS, Gonzalez LF, Srinivas K, Auld DJ, Wong KC. Aerodynamic shape optimisation of unmanned aerial vehicles using hierarchical asynchronous parallel evolutionary algorithms. International Journal of Computational Intelligence Research. 2007 Jan; 3(3):229-50.

30. Tianyuan H, Xiongqing Y. Aerodynamic/stealthy/structural multidisciplinary design optimization of unmanned combat air vehicle. Chinese Journal of Aeronautics. 2009 Aug; 22(4):380-6.

31. Jaeger L, Gogu C, Segonds S, Bes C. Aircraft multidisciplinary design optimization under both model and design variables uncertainty. Journal of Aircraft. 2013 Feb; 50(2):528-38.
32. A robust approach to pre-concept design of UCAV considering survivability [Internet]. [cited 2002 Sep 04]. Available from: http://arc.aiaa.org/doi/abs/10.2514/6.2002-5605.

33. Evaluation of multidisciplinary optimization approach for aircraft conceptual design [Internet]. [cited 2004 Aug 30]. Available from: http://arc.aiaa.org/doi/abs/10.2514/6.20044537.

34. Sobester A, Keane AJ. Multidisciplinary design optimization of UAV airframes. Newport, Rhode Island: 47th AIAA/ ASME/ASCE/AHS/ASC Structures, Structural Dynamics, and Materials Conference - AIAA; 2006 May. p. 1-13.

35. Multidisciplinary unmanned combat air Vehicle-UCAV design optimization using variable complexity modeling [Internet]. [cited 2009 Sep 21]. Available from: http://arc. aiaa.org/doi/abs/10.2514/6.2009-7093.

36. Bin $H$, Justice A. The design of an unmanned aerial vehicle based on the ArduPilot. Indian Journal of science and Technology. 2009 Apr; 2(4):12-15.

37. Choi SM, Nhu-Van Nguyen, Kim SW-S, Lee J-W, Byun Y-H. Multidisciplinary Unmanned Combat Air Vehicle (UCAV) system design using multi-fidelity analysis. $48^{\text {th }}$ AIAA Aerospace Sciences Meeting Including the New Horizons Forum and Aerospace Exposition; 2010 Jan. p. 1-16.

38. Preliminary aircraft design in a collaborative multidisciplinary design environment [Internet]. [cited 2011 Sep 20]. Available from: http://arc.aiaa.org/doi/pdf/10.2514/6.20116959. Date Accessed: 20/09/2011.

39. Multiobjective Conceptual design of an unmanned combat air vehicle [Internet]. [cited 2012 Sep 17]. Available from: http://arc.aiaa.org/doi/abs/10.2514/6.2012-5532. 